\title{
Rationale of an economically driven PD1 biomarker development in lung cancer - an academic dilemma
}

\author{
Wolfgang Hilbe $\cdot$ Rupert Bartsch $\cdot$ Christoph Zielinski
}

Received: 22 July 2016 / Accepted: 27 July 2016 / Published online: 29 August 2016

(C) Springer-Verlag Wien 2016

Immunotherapies for second line use in lung cancer have proven to add relevant value compared to standard treatment options [1-3]; indeed, they are deemed a breakthrough in cancer treatment. The "clinical value" of a certain drug is determined by its effects on relevant endpoints, namely overall survival, tolerability, and quality of life. From a historical perspective, at least two of these three endpoints should be achieved to accept a new treatment option to be beneficial. Monoclonal antibodies targeting the PD1 and PD-L1 receptors have achieved these endpoints. Due to their mode of action the presence of these targets should-per definition-be prerequisite for their clinical application. However, the short history of "targeted therapies" has told us to be cautious and that simplified explanations of potential drug effects were sometimes misleading.

In breast cancer, the development of HER2-targeted therapy was a unique story of success: As early as 1987, HER2-protein over-expression was identified as a strong predictor of poor outcome [4] resulting in the rational development of the monoclonal antibody trastuzumab in metastatic [5] as well as in early-stage breast cancer [6]. However, in the early years the definition of cut-off points concerning immunohistochemistry and even more the implementation of FISH analysis gave room for intensive discussions over many years until the algorithms for diagnostic workup were generally accepted.

\footnotetext{
W. Hilbe, MD ( $\triangle)$

Wilhelminenspital der Stadt Wien,

Montleartstrasse 37, 1160 Vienna, Austria

wolfgang.hilbe@wienkav.at
}

R. Bartsch, MD · C. Zielinski, MD

Internal Medicine, Medical University Vienna, Währinger

Gürtel 18-20, 1190 Vienna, Austria
In lung cancer as early as 2003, gefitinib was presented as a new and exciting drug developed to block the epithelial growth factor (EGF) signaling pathway in lung cancer [7]. Since most of lung cancers showed an increased EGF-receptor (EGFR) expression, a broad use of this "lung cancer pill" was promoted. However, in an unselected population, clinical effects were quite moderate at best or non-existing at all. In the clinical routine setting some predictors of response were identified [8]: Patients with an adenocarcinoma more likely benefited than those with a squamous cancer type, but some of the latter responded as well. Female sex, Asian ethnicity, and never-smoker status were also discriminators of greater activity, but again the other patients showed responses too, therefore these clinical parameters did not allow excluding single patients from this treatment option. By analyzing the tissue of patients showing extensive responses, a correlation with specific mutations within the gene coding for EGFR were identified [9]. Subsequently, the EGFR story changed dramatically. Patients harboring EGFR mutations clearly benefited from treatment with an EGFR-TKI, while on the other hand, in EGFR wild-type tumors standard platinum doublet-based chemotherapy was superior [10].

Facing recent developments concerning the monoclonal antibodies targeting PD1 or PD-L1 some dejavues appear. Again a rationally developed new class of drugs was presented interacting with a well-defined target molecule. Again we are able to identify those patients benefiting more than others by using immunohistochemical assays testing PD-L1 expression; however in the cohort of patients with PD-L1 negative tumors, substantial responses were also observed; moreover they benefited in terms of less toxicity and improved quality of life. The high economic burden of these new drugs, however, triggered an enormous effort for the implementation of selection criteria whom 
to treat or not to treat. Yes, we are able to analyze and quantify the expression levels and these reports, although not linked to the approval of the drug, are already listed in pathological reports. But as a clinician facing the individual patient, should I refuse this treatment option just based on a biomarker which failed to prove its predictive value? Each treatment for a patient has to outweigh risks and benefits considering potential alternatives. Facing this dilemma, the FDA summarized in their reports $[11,12]$ that further studies are needed to identify better predictive biomarkers and to explore the utility of PD-L1 testing.

Every society may define their economic limitations regarding what costs a community is willing to spend for their health care system or for an individual patient. In the light of expensive albeit non-curative treatments, the cut-off of this cost-benefit balance is even more difficult to define.

In conclusion, implementation of biomarkers without clinical validation, just based on economic limitations, is unethical. Nevertheless, the medical community should collect biosamples and strive to improve our knowledge on the mode of action and hopefully offering biomarkers allowing the application of these new drugs to selected patients properly in the near future.

Conflict of interest W. Hilbe, R. Bartsch, and C. Zielinski declare that they have no competing interests.

\section{References}

1. Brahmer J, Reckamp KL, Baas P, et al. Nivolumab versus docetaxel in advanced squamous-cell non-small-cell lung cancer. NEngl J Med. 2015;373(2):123-35.

2. Borghaei H, Paz-Ares L, Horn L, et al. Nivolumab versus docetaxel in advanced nonsquamous non-small-cell lung cancer. NEngl J Med. 2015;373(17):1627-39.
3. Herbst RS, Baas P, Kim DW, et al. Pembrolizumab versus docetaxel for previously treated, PD-L1-positive, advanced non-small-cell lung cancer (KEYNOTE-010): a randomised controlled trial. Lancet. 2016;387(10027):1540-50.

4. Slamon DJ, Clark GM, Wong SG, Levin WJ, Ullrich A, McGuire WL. Human breast cancer: correlation of relapse and survival with amplification of the HER-2/neu oncogene. Science. 1987;235(4785):177-82.

5. Slamon DJ, Leyland-Jones B, Shak S, et al. Use of chemotherapy plus a monoclonal antibody against HER2 for metastatic breast cancer that overexpresses HER2. NEngl J Med. 2001;344(11):783-92.

6. Piccart-Gebhart MJ, Procter M, Leyland-Jones B, et al. Trastuzumab after adjuvant chemotherapy in HER2positive breast cancer. NEnglJ Med. 2005;353(16):1659-72.

7. Fukuoka M, Yano S, Giaccone G, et al. Multi-institutional randomized phase II trial of gefitinib for previously treated patients with advanced non-small-cell lung cancer (The IDEAL 1 Trial). JClin Oncol. 2003;21(12):2237-46.

8. Thatcher N, Chang A, Parikh P, et al. Gefitinib plus best supportive care in previously treated patients with refractory advanced non-small-cell lung cancer: results from a randomised, placebo-controlled, multicentre study (Iressa Survival Evaluation in Lung Cancer). Lancet. 2005;366(9496):1527-37.

9. Lynch TJ, Bell DW, Sordella R, et al. Activating mutations in the epidermal growth factor receptor underlying responsiveness of non-small-cell lung cancer to gefitinib. NEngl J Med. 2004;350(21):2129-39.

10. Mok TS, Wu YL, Thongprasert S, et al. Gefitinib or carboplatin-paclitaxel in pulmonary adenocarcinoma. NEngl J Med. 2009;361(10):947-57.

11. Kazandjian D, Suzman DL, Blumenthal G, et al. FDA approval summary: Nivolumab for the treatment of metastatic non-small cell lung cancer with progression on or after platinum-based chemotherapy. Oncologist. 2016;21(5):634-42.

12. Sul J, Blumenthal GM, Jiang X, et al. FDA approval summary: Pembrolizumab for the treatment of patients with metastatic non-small cell lung cancer whose tumors express programmed death-ligand. Oncologist. 2016;21(5):643-50. 